\title{
Measuring consumers' preferences for craft beer attributes through Best-Worst Scaling
}

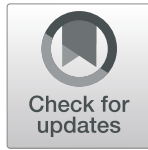

\author{
Marco Lerro ${ }^{*}$ D, Giuseppe Marotta and Concetta Nazzaro
}

\author{
* Correspondence: mrlerro@ \\ unisannio.it \\ Department of Law, Economics, \\ Management and Quantitative \\ Methods, University of Sannio, \\ Piazza Arechi II, 82100, Benevento, \\ BN, Italy
}

\begin{abstract}
The current paper investigates consumers' consumption behavior and preferences for craft beer. More specifically, it uncovers consumers' consumption habits and perception about craft beer, as well as their preferences for 13 beer attributes drawn from the literature.

The analysis was carried out in Italy by administering a structured questionnaire to 323 consumers. Best-Worst Scaling was used to detect consumers' preferences towards the 13 craft beer attributes. The latter were then ranked on the basis of their best-worst scores to identify the level of importance Italian consumers assign to the different attributes.

The study findings reveal that Italian craft beer consumers are young, well-educated, and employed. They drink craft beer more than once per month, mainly in pub and with friends and colleagues. Craft beer is perceived with higher quality and different flavors, while compared with a commercial beer, it results tastier, more genuine, and natural. As for the beer attributes, Italians prefer taste, fermentation process, and color, while store promotion, brand, and price rank as the least important. The study findings offer several implications for brewers and marketers involved in the beer sector. Based on the preferences detected, breweries should adapt their product offer to meet craft beer consumers' expectations.
\end{abstract}

Keywords: Beer, Beer choice and consumption, Italian consumers, BWS

\section{Introduction}

Over the last decades, the European beer sector has been shaken up by the rising interest of consumers towards beers produced on small scale and slower fermentation process, namely craft beers (Carvalho et al. 2018). The creators of this astonishing renaissance, that positively affect the whole beer sector ${ }^{1}$, are mainly the microbreweries ${ }^{2}$ (approximately 7900 in Europe, in 2017) (The brewers of Europe 2018) that were able to rethink the product and the sector focusing on high quality, variety, and uniqueness (Calvo-Porral et al. 2017; Muggah and McSweeney 2017). Further, they were sensitive to the dynamic consumers' expectations and consumption habits which have generated new business opportunities promptly seized by breweries. On the one hand, health issues have significantly affected consumers' consumption habits inducing them to a more conscious and responsible consumption (Donadini et al. 2016; Nazzaro et al.

\footnotetext{
${ }^{1}$ The European beer sector counted, in 2017, approximately 9500 active breweries, represented for roughly three-quarters by microbreweries and small and medium enterprises (The brewers of Europe 2018).

${ }^{2} \mathrm{~A}$ brewery with an annual beer production up to 1000 hectoliters (The brewers of Europe 2018).
} 
2018). On the other hand, the current consumers are wealthier, more involved with the product, and adventurous in terms of taste (Aquilani et al. 2015; Donadini and Porretta 2017). Accordingly, they seek pricier beers able to express the typicality and authenticity of the territory of production (Donadini et al. 2016; Aquilani et al. 2015) and arouse "pleasure, enjoyment, identity and recognition" (Donadini and Porretta 2017, page 183). In a market dominated by industrial mass market producers, microbreweries rely on these perceptions to differentiate their offer and drive the premiumization of the product (Muggah and McSweeney 2017).

Although the craft beer market is promising, it represents still a fraction of the commercial one mainly due to the lack of involvement of large-scale producers. To sustain this growth, breweries may need to look either at new beer consumers (e.g., female and younger attracted by different flavors) or draw on current commercial beer consumers (Donadini and Porretta 2017; Donadini et al. 2016). However, to attract new consumers, breweries have to balance the innovative elements of craft beers with consumers' expectations. Unlocking these expectations become crucial to create a widely accepted product, able to preserve the positive momentum of the sector and revive its economic outlook.

The current paper investigates consumers' consumption behavior and preferences for craft beer. More deeply, the aims of the study are twofold: (i) uncovering consumers' consumption habits and perception about craft beer and (ii) detecting consumers' preferences for as many as 13 craft beer attributes. Specifically, the study addressed the following research question: Do consumers have heterogeneous preferences for different craft beer attributes?

The study focuses on both consumer and product. Purchasing decision, in fact, is the result of the complex interaction between internal factors of consumers (e.g., sociodemographic characteristics and cultural values) (Nazzaro et al. 2019; Lerro et al. 2019) and product attributes (i.e., intrinsic and extrinsic attributes) (Jover et al. 2004). CalvoPorral et al. (2018) highlighted that consumers' culture affects both product choice (e.g., the choice of packaging materials and size) and beer consumption occasion (e.g., when alcoholic beverages are consumed). Product attributes, instead, affect purchasing decisions acting on the perceived product quality (Charters and Pettigrew 2007). When consumers have previously experienced the product, intrinsic attributes (e.g., color, flavor, and smell) play a decisive role in the purchasing process (Boncinelli et al. 2019; Jover et al. 2004; Sáenz-Navajas et al. 2013). Conversely, in common purchasing situation, in which consumers cannot experience the product before the purchase, the choice is taken relying on a bundle of quality cues (i.e., extrinsic attributes) (Schäufele and Hamm 2018; Sáenz-Navajas et al. 2013; Mueller and Szolnoki 2010). For instance, to decrease the perceived risks related to purchase, consumers adopt heuristic strategies based on several product attributes such as price, brand, packaging, and labeling (Boncinelli et al. 2019; Sáenz-Navajas et al. 2013).

Literature on consumers' consumption behavior and preferences towards craft beer is still scant (Donadini and Porretta 2017; Aquilani et al. 2015). Research on Italian consumers-that are the focus of the current study-is limited as well (Aquilani et al. 2015). A reasonable explanation resides in the role played by the country in the European beer scenario. Albeit, in terms of per-capita beer consumption, Italy place among the last positions (i.e., third last) in Europe, the country ranks ninth (15 million 
hectoliter) as regards beer production, fourth for number of active brewery companies (i.e., 864), and fifth for microbreweries established (i.e., 693) (The Brewers of Europe 2018).

Accordingly, investigating consumers' preferences would enable to release-on the market-new products able to meet consumers' expectations. Indeed, the new product would be developed based on consumers' expectations rather than on brewer's creativity and intuition. The result is a revamp of the Italian beer sector able to attract new consumers and sustain its economic growth.

The paper is structured as follows. The next section outlines the methodology implemented in the study focusing on data gathering, the questionnaire administered, and the beer attributes investigated in the study. Sample characteristics, consumers' consumption habits, and preferences towards the beer attributes are presented in the "Results" section. Lastly, the "Discussion" section fully discusses the study findings, while the "Conclusion" section draws implications for brewers and marketers involved in the beer sector.

\section{Methodology}

\section{Data collection and questionnaire}

An empirical analysis was carried out to address the aims of the study interviewing a convenience sample of Italian consumers. Participants were screened to eligibility to take part in the study based on their age and craft beer consumption. Specifically, they had to be consumers of craft beer ${ }^{3}$ older than 18 years. Data collection took approximately 4 months (from December 2018 to April 2019) by administering a web-based structured questionnaire. Participants were invited to take part in the study through different messaging and social platforms (e.g., email, WhatsApp, Facebook, Twitter). A message introducing the general aim of the study was sent to consumers followed by a link redirecting to the online questionnaire. To avoid social desirability bias among participants, the message clearly explicit that the questionnaire was anonymous and all information gathered were used only for the purpose of the study and in an aggregated way. Further, questionnaire completion was facilitated by the possibility to interrupt and resume it at a later time. To detect potential misinterpretation in the languages used as well as in the way of posing the questions, a pilot test with a small group of consumers (i.e., 20) was carried out. The latter did not reveal any critical issues. Lastly, no monetary compensation was provided to participants to encourage participation and completion of the questionnaire. Overall, 410 Italian consumers participated in the study, while 323 questionnaires were deemed full and used for the descriptive and statistical analysis.

The administered questionnaire consisted of three sections, lasting on average 15 min. The first section detected consumers' consumption habits and perception about craft beer. In more detail, a battery of eight questions-related to craft beer-were posed to consumers investigating (i) frequency of consumption, (ii) purchasing by price point levels, (iii) place of purchase, (iv) place of consumption, (v) consumption occasion, (vi) people with whom is consumed, (vii) craft beer perception, and (viii) evaluation of a craft beer compared to a commercial one. Consumers' frequency of

${ }^{3}$ The screening question did not detect the frequency of craft beer consumption that instead was collected in the first section of the questionnaire. 
consumption was assessed on a six-point semantic scale for frequency $(1=$ more than once per week, $2=$ once per week, $3=2-3$ times per month, $4=$ once per month, $5=$ once per 3 months, 6 = less than once per 3 months). Thus, respondents were asked to express how much they usually spend for a 0.331 bottle of craft beer among five price levels starting from " $<€ 2.00$ " and ending with "> $€ 8.00$ " (with an interval of $€ 2.00$ between each level). Four most frequent places of purchase were addressed in the study (i.e., directly at the producer, grocery store, pub/restaurant, and online), while as for place of consumption, consumers may express their preferences among five options such as "at home," "at friends' home," "bar," "pub," and "restaurant." Further, consumers had to state their favorite craft beer consumption occasion choosing among "lunch," "aperitif," "dinner," "after dinner," "during a break," "party," and whether they consume craft beer "alone" or with other people such as "friends/colleagues" or "family." The analysis also uncovered consumers' perception of craft beer and their evaluation compared to a commercial one. As for the former, respondents were asked to express their perception about craft beer according to seven statements, that are, "It has a different flavor," "It is produced in small quantities," "It is a high-quality beer," "It is a home brew beer," "It is brew with organic ingredients," "It is an unpasteurized beer," and "It is brew with artificial flavors." Then, craft beer was posed in relation to a commercial one ${ }^{4}$, and consumers had to state whether they perceive it tastier, more genuine, more digestible, healthier, more natural, and more refreshing. For all measurements, consumers were forced to choose only one option among those displayed. The second section of the questionnaire explored consumers' preferences for $13 \mathrm{craft}$ beer attributes drawn from the literature (Aquilani et al. 2015; Donadini and Porretta 2017; Muggah and McSweeney 2017) addressing the BestWorst Scaling (BWS) experiment. Socio-demographics characteristics of respondents such as gender, age, household size, education level, occupation, and annual family income were then collected in the end section of the questionnaire.

\section{Craft beer attributes and Best-Worst Scaling implementation}

The current study investigated Italians' preferences for as many as 13 craft beer attributes. The latter are drawn from previous studies and represent the factors more likely to affect consumer decisions when purchasing a craft beer (Donadini and Porretta 2017; Muggah and McSweeney 2017; Donadini et al. 2016; Aquilani et al. 2015). Table 1 shows the craft beer attributes assessed in the analysis.

The methodology implemented to assess consumers' preferences was Best-Worst Scaling. The latter, also known as maximum difference scaling, was initially applied by Finn and Louviere (1992) in a study on food safety. Currently, BWS is widely applied in several social science studies involving consumer behavior (Auger et al. 2007; Burke et al. 2014), food preferences (Lusk and Briggeman 2009), and wine marketing (Cohen 2009; Goodman et al. 2008; Pomarici et al. 2017). The recent interest towards this approach lies mainly in the benefits related to its implementation. Firstly, BWS assumes that respondents can easily determine the most and the least preferred option (also called the best and the worst), among a defined set of choices (Auger et al. 2007; Jaeger et al. 2008; McDonald and Rundle-Thiele 2008). BWS does not allow to express a preference for each option, but instead, it forces respondents to

${ }^{4}$ The question did not refer to a specific brand, i.e., "In your opinion, a craft beer compared to a commercial one is..." 
Table 1 Craft beer attributes considered by consumers when purchasing a beer

\begin{tabular}{ll}
\hline Attribute number & Attributes \\
\hline 1 & Alcohol content \\
2 & Brand name \\
3 & Store promotion \\
4 & Someone recommended it \\
5 & Price \\
6 & Packaging size \\
7 & Color (amber, dark, blonde) \\
8 & Country of origin \\
9 & Special grains (wheat, corn) \\
10 & Certification (organic) \\
11 & Taste \\
12 & Packaging material (glass, can) \\
13 & Fermentation process (high/low fermentation) \\
\hline
\end{tabular}

trade-offs among options to identify those most and least preferred (Flynn et al. 2007). They are the maximally different pair options and, in accordance with the random utility theory (McFadden, 1974), are also those providing the highest and lowest utility. Secondly, the approach is devoid of bias affecting rating scales that, in turn, ensure scalar equivalence in crosscountry studies (Cohen 2009; Mueller and Lockshin 2013). Respondents' choices are taken on the basis of an underlying latent scale that in the current study is the level of importance consumers attach to the different craft beer attributes (Louviere and Islam 2008).

The values of the attributes are mostly obtained running a multinomial logit model (Marley and Louviere 2005). However, a fair approximation of model results is achieved by the difference between the frequency an attribute is chosen as most important and the one it is chosen as least important (Cohen 2009). The latter occurs when the experimental design is balanced so that the attributes are organized in choice sets in a balance incomplete block (BIB) design. BIB design enables to have a full ranking of the attributes investigated, assessing them in different choice sets (Cohen 2009). Literature reveals that respondents can assess from four to six attributes per choice set and up to 20 choice sets before getting bothered about the task.

The current study adopted the BW design developed by Cohen (2009). Specifically, the study applied a 13,4,4,1 BIB design in which 13 attributes are assessed in 13 choice sets, with four attributes each, appearing four times across choice sets.

In this study, respondents had to indicate the most and the least important attributes when purchasing a craft beer at the grocery store. The scenario refers to a common purchase situation. Indeed, in a different situation or special occasion, consumers' behavior and preferences may differ. An example of the choice sets showed to participants is presented in Table 2.

\section{Results}

\section{Sample description}

Table 3 illustrates descriptive statistics of the overall sample. It results fairly distributed among gender (52\% of the sample is female) and within an age range of 18 and 72 years (mean age is $30.6, \pm 11.5$ ). 
Table 2 Example of a B-W choice set presented to respondents

\begin{tabular}{ccc}
\hline $\begin{array}{l}\text { Imagine you are at your usual grocery store, which of these attributes do you think are the } \\
\text { most important and least important when purchasing a craft beer (choose only one as most } \\
\text { important and one as least important)? }\end{array}$ \\
\hline Most important & Taste & Least important \\
\hline$\square$ & Country of origin & $\square$ \\
$\square$ & Alcohol content & $\square$ \\
$\square$ & Certification (organic) & $\square$ \\
\hline
\end{tabular}

On average, respondents live in families consisting of four members $( \pm 1.0)$ and up to nine members. The majority of interviewed are highly educated with more than half of them holding a high school degree (58\% of the sample) and a third a university degree (33\% of the sample). As for occupation, one out of three respondents is employed (31\% of the sample), while roughly half is student (48\%). Lastly, respondents live in families with an annual income falling into two main groups: below $€ 20,000$ (38\% of the sample) and between $€ 20,000$ and 40,000 (43\%).

\section{Craft beer consumption habits}

The study findings show that the interviewed are regular consumers of craft beer (Table 4). Indeed, more than 40 percent of respondents stated to drink craft beer

Table 3 Sample descriptive statistics ( $N=323)$

\begin{tabular}{|c|c|c|c|c|c|}
\hline Variable name and description & Mean & Frequency (\%) & Standard deviation & Min & Max \\
\hline Gender ( 1 if female) & 0.520 & & $\mathrm{~N} / \mathrm{A}$ & 0 & 1 \\
\hline Respondent's age & 30.674 & & 11.520 & 18 & 72 \\
\hline Household size & 4.077 & & 1.076 & 1 & 9 \\
\hline Education level classes & 3.424 & & 0.661 & 1 & 5 \\
\hline Primary school & & 0.3 & & & \\
\hline Secondary school & & 2.5 & & & \\
\hline High school & & 57.9 & & & \\
\hline University degree & & 33.1 & & & \\
\hline Above university degree & & 6.2 & & & \\
\hline Occupation status & 2.476 & & 1.221 & 1 & 6 \\
\hline Employed & & 30.9 & & & \\
\hline Self-employed & & 12.1 & & & \\
\hline Housewife/Husband & & 2.8 & & & \\
\hline Retired & & 0.3 & & & \\
\hline Student & & 48.6 & & & \\
\hline Unemployed & & 5.3 & & & \\
\hline Annual family income classes & 1.913 & & 0.970 & 1 & 5 \\
\hline$<€ 20,000$ & & 38.1 & & & \\
\hline$€ 20,000-40,000$ & & 43.0 & & & \\
\hline$€ 41,000-60,000$ & & 11.5 & & & \\
\hline$€ 61,000-80,000$ & & 4.3 & & & \\
\hline$>€ 80,000$ & & 3.1 & & & \\
\hline
\end{tabular}


monthly, and one out of three on a weekly basis (13\% more than once per week, $16 \%$ once per week). They stated to spend for a 33-cl bottle of craft beer between 4 and 6 euro (48\% of the sample), and they purchase it mostly in pub or restaurant (75\%), immediately followed by grocery store (13\%). The analysis revealed that the place of purchase reflects the place of consumption. Indeed, the majority consume craft beer in pubs (69\% of the sample), while the consumption at home is preferred by nearly 20 percent of the sample. The main occasion to drink craft beer is mainly at dinner (65\% of the sample) with friends and colleagues (85\%). Roughly half of the sample perceive craft beer of higher quality (48\%), while a third with a different flavor (33\%). Lastly, respondents perceive a craft beer as tastier (42\% of the sample), more natural (23\%), and more genuine (22\%) compared to a commercial beer.

\section{Best-worst Scaling analysis}

The $\mathrm{B}-\mathrm{W}$ score of the attributes is generated by subtracting the number of times an attribute is chosen as the least important from the number of times it is chosen as the most important. Since each attribute appeared overall four times in the 13 choice sets, the individual $\mathrm{B}-\mathrm{W}$ score fall into a range from +4 to -4 . The overall $\mathrm{B}-\mathrm{W}$ score for each attribute is then calculated adding up the scores at individual level of each attribute. Table 5 presents the B-W scores and the average B-W scores of the attributes investigated. Consumers' preferences are obtained by ranking the craft beer attributes according to their B-W score. A positive B-W score implies that the times an attribute is chosen as most important are more than those it is selected as least important. Accordingly, consumers assign great value to the attribute. Conversely, negative values express a lower consumers' interest towards the attribute. In this scenario, in fact, the number of times an attribute is chosen as least important exceeds the times it is chosen as most important.

As shown in Fig. 1, seven out of 13 attributes were valued by consumers more positively than negatively. In more detail, the three most important attributes considered by consumers when purchasing a craft beer are all related to product intrinsic characteristics, namely taste $(0.430)$, fermentation process $(0.265)$, and color $(0.252)$. By contrast, brand name $(-0.231)$, store promotion $(-0.295)$, and packaging size $(-0.402)$ have the least effect in driving consumers purchasing decisions (B-W score $<0)$.

To evaluate whether the means of the ranked attributes were statistically significantly different, a paired-samples $t$ test was performed across all pairs of craft beer attributes (Table 6). Few pairs of attributes are not significantly different, as shown by a $p$ value higher than 0.05 . Specifically, the difference in the attributes is not equal to zero between "fermentation process (high/low fermentation)" and "color (amber, dark, blonde)" as well as between "certification (organic)," "country of origin," and "someone recommended it." Further, "country of origin" and "special grains (wheat, corn)" are not significantly different, likewise the latter with "someone recommended it." Lastly, "alcohol content" is not significantly more important than "price" and "brand name," nor is "brand name" compared to "store promotion."

\section{Discussion}

The analysis outlined a profile of craft beer consumer with an average age of 31 years, well educated (i.e., $58 \%$ of the sample hold a high school degree and $33 \%$ a university 
Table 4 Respondents' craft beer consumption habits

\begin{tabular}{|c|c|}
\hline Variable name and description & Frequency (\%) \\
\hline \multicolumn{2}{|l|}{ Craft beer consumption frequency } \\
\hline More than once per week & 13.6 \\
\hline Once per week & 16.4 \\
\hline 2-3 times per month & 13.6 \\
\hline Once per month & 27.5 \\
\hline Once per 3 months & 13.6 \\
\hline Less than once per 3 months & 15.2 \\
\hline \multicolumn{2}{|l|}{ Craft beer by price points } \\
\hline$<€ 2.00$ & 1.8 \\
\hline Between $€ 2.01$ and 4.00 & 34.1 \\
\hline Between $€ 4.01$ and 6.00 & 48.3 \\
\hline Between $€ 6.01$ and 8.00 & 12.4 \\
\hline$>€ 8.00$ & 3.4 \\
\hline \multicolumn{2}{|l|}{ Favorite craft beer place of purchase } \\
\hline Directly at the producer & 9.3 \\
\hline Grocery store & 12.8 \\
\hline Pub/restaurant & 74.9 \\
\hline Online & 1.5 \\
\hline Others (most frequently mentioned: bar) & 1.5 \\
\hline \multicolumn{2}{|l|}{ Favorite craft beer place of consumption } \\
\hline At home & 14.8 \\
\hline At friends' home & 5.2 \\
\hline Bar & 4.0 \\
\hline Pub & 69.0 \\
\hline Restaurant & 5.9 \\
\hline Others (most frequently mentioned: producer) & 0.9 \\
\hline \multicolumn{2}{|l|}{ Favorite craft beer consumption occasion } \\
\hline Lunch & 1.2 \\
\hline Aperitif & 4.0 \\
\hline Dinner & 65.0 \\
\hline After dinner & 17.4 \\
\hline During a break & 1.9 \\
\hline Party & 10.5 \\
\hline \multicolumn{2}{|l|}{ People with whom craft beer is consumed } \\
\hline Family & 13.6 \\
\hline Alone & 1.3 \\
\hline Friends/colleagues & 85.1 \\
\hline \multicolumn{2}{|l|}{ Craft beer perception } \\
\hline It has a different flavor & 33.1 \\
\hline It is produced in small quantities & 6.8 \\
\hline It is a high-quality beer & 47.7 \\
\hline It is a home brew beer & 5.0 \\
\hline It is brew with organic ingredients & 4.0 \\
\hline It is an unpasteurized beer & 2.8 \\
\hline
\end{tabular}


Table 4 Respondents' craft beer consumption habits (Continued)

\begin{tabular}{ll}
\hline Variable name and description & Frequency (\%) \\
\hline It is brew with artificial flavors & 0.6 \\
Craft beer vs commercial beer evaluation & 41.8 \\
It is tastier & 22.3 \\
It is more genuine & 3.4 \\
It is more digestible & 9.6 \\
It is healthier & 22.9 \\
It is more natural & 0.0 \\
It is more refreshing & \\
\hline
\end{tabular}

degree), and an annual family income in the range $€ 20,000$ and 40,000 . This profile is in accordance with previous studies carried out in different countries. For instance, Aquilani et al. (2015) revealed that the majority of Italian beer consumers are younger than 33 years old, while in Brazil, more than half of consumers fall in the age range from 19 to 39 years and are well educated (roughly $20 \%$ of the sample hold a university degree) (Carvalho et al. 2018). The existence of a core made up of young consumers is promising. Indeed, as consumers become used to drink craft beer, the likelihood of a higher consumption increases as well (Carvalho et al. 2018). Further, their children, having grown with the product, are more likely to become future consumers of craft beer. The level of education, instead, supports the profile drawn by the literature of a consumers involved in the product and in its unique characteristics.

As for consumption habits, a third of the sample stated to drink craft beer weekly and more than half monthly. The analysis also revealed the social role associated with beer consumption. Indeed, craft beer is consumed mainly in pub, after dinner, and with friends and colleagues. Socialization is becoming a relevant component for craft beer consumers who assign a relaxing and informal connotation to the consumption. As a result, consumers are more likely to consume craft beer with friends and peers. Consumers consider craft beer as a beer with high quality and different flavor, as well as tastier, more genuine, and natural than a commercial one. The latter may suggest a

Table 5 Importance of craft beer attributes by respondents (ranked by B-W score)

\begin{tabular}{lllll}
\hline Attribute number & Attributes & Total best & Total worst & B-W score \\
\hline 11 & Taste & 595 & -39 & 556 \\
13 & Fermentation process (high/low fermentation) & 476 & -134 & 342 \\
7 & Color (amber, dark, blonde) & 440 & -114 & 326 \\
10 & Certification (organic) & 347 & -170 & 177 \\
8 & Country of origin & 305 & -159 & 146 \\
4 & Someone recommended it & 332 & -237 & 95 \\
9 & Special grains (wheat, corn) & 287 & -227 & 60 \\
12 & Packaging material (glass, can) & 199 & -286 & -87 \\
1 & Alcohol content & 165 & -369 & -204 \\
5 & Price & 160 & -370 & -210 \\
2 & Brand name & 110 & -409 & -299 \\
3 & Store promotion & 121 & -502 & -381 \\
6 & Packaging size & 50 & -569 & -519 \\
\hline
\end{tabular}




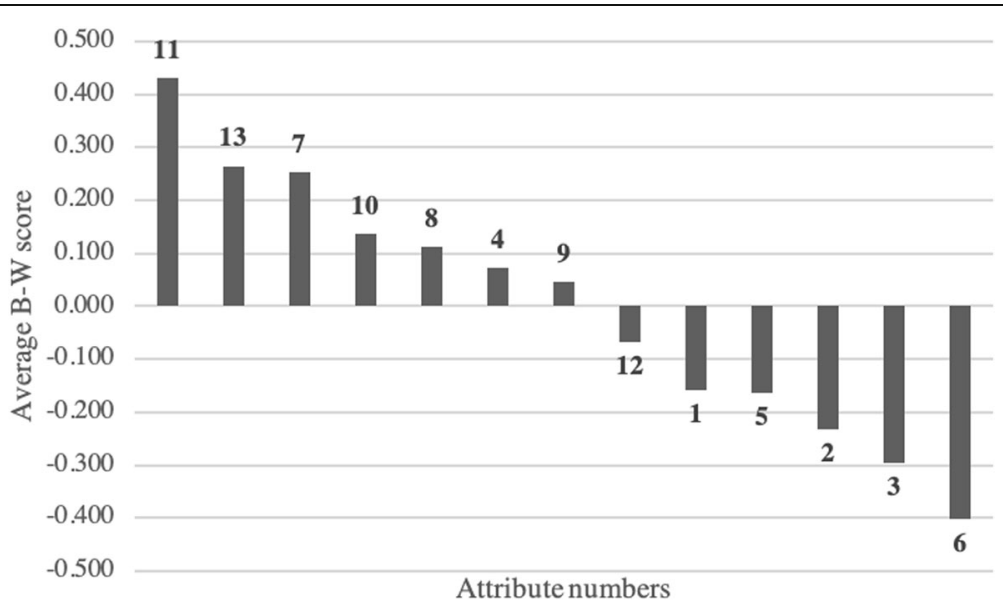

Fig. 1 B-W average scores of craft beer attributes that influence Italian consumers when purchasing a beer

higher involvement with the product as well as the desire to experience beers with different tastes and flavors, common characteristics of craft beers. Lastly, they are willing to spend between 4 and 6 euros for a 33-cl bottle of craft beer. These findings are in line with previous studies in different European countries. Donadini et al. (2016) in Italy showed that $38 \%$ of respondents drink beer sometimes per week, while among Belgium consumers, this percentage goes up to 46\% (Poelmans and Rousseau 2017). In addition, according to Aquilani et al. (2015), Italians drink beer mostly in pub. Lastly, a recent study carried out in Spain identified five clusters of beer consumers (Calvo-Porral et al. 2018). Among these, two clusters (i.e., "beer lovers" and "social drinkers") well synthesize the Italian scenario. The so-called beer lovers are consumers younger than 30 years who drink beer frequently; they are interested in product quality and are willing to pay more for a beer (Calvo-Porral et al. 2018). The "social drinkers," instead, see the social factors related to beer consumption (Calvo-Porral et al. 2018). Consumers belonging to this group experience beer with friends and peers mainly outside the home.

Table 6 Mean comparison of craft beer attributes for respondents

\begin{tabular}{|c|c|c|c|c|c|c|c|}
\hline & Attributes & Average B-W score & \multicolumn{5}{|c|}{ Mean-comparison* } \\
\hline 11 & Taste & 0.430 & & & & & \\
\hline 13 & Fermentation process (high/low fermentation) & 0.265 & $x$ & & & & \\
\hline 7 & Color (amber, dark, blonde) & 0.252 & $x$ & & & & \\
\hline 10 & Certification (organic) & 0.137 & $x$ & & & & \\
\hline 8 & Country of origin & 0.113 & $x$ & $x$ & & & \\
\hline 4 & Someone recommended it & 0.073 & $x$ & & $x$ & & \\
\hline 9 & Special grains (wheat, corn) & 0.046 & & $x$ & $x$ & & \\
\hline 12 & Packaging material (glass, can) & -0.067 & & & & & \\
\hline 1 & Alcohol content & -0.158 & & & & $x$ & \\
\hline 5 & Price & -0.162 & & & & $x$ & \\
\hline 2 & Brand name & -0.231 & & & & $x$ & $x$ \\
\hline 3 & Store promotion & -0.295 & & & & & $x$ \\
\hline 6 & Packaging size & -0.402 & & & & & \\
\hline
\end{tabular}

Note: *paired $\mathrm{t}$ test $p<0.05$; attributes with $\mathrm{Xs}$ in the same column or row are not significantly different 
As for the craft beer attributes, consumers show to favor taste overall. Shortly after, they chose-as the most important attributes-the fermentation process, color, certification, and country of origin. These attributes directly affect the sensory characteristics of the product and are crucial for craft beer that relies on specific characteristics such as a distinguishable taste and texture to differentiate from commercial beer. Indeed, it is the expectation of tasting a beer with a unique flavor and that expresses the uniqueness of a territory to push consumers to drink a craft beer. Conversely, Italian consumers are less interested in packaging material, store promotion, brand, and price. The lack of importance assigned to store promotion, brand, and price is expected. Indeed, it is acknowledged that craft beer consumers are willing to pay higher prices for quality beers characterized by special tastes (Carvalho et al. 2018). Accordingly, they may result less sensitive to price and promotions. The importance of the brand in the purchasing decision is mainly due to previous consumers' experiences. However, in the current market scenario characterized by new players entering the market and consumers inclined to experience different products, brand plays a minor role compared to other attributes. In addition, the low importance attached to store promotion, brand, and price may also be explained by the methodology applied in the study for detecting consumers' preferences (i.e., BWS) and by its hypothetical nature. Similar to the study findings, Donadini and Porretta (2017) uncovered a consumers' preference for, among other, brewing technology, while less interest for retail price. Further, when purchasing a beer, Belgian consumers rate taste, type, and color as the top three most important attributes (Poelmans and Rousseau 2017). Brazilian consumers share similar preferences in terms of craft beer attributes ranking quality as most important, followed by type, brand, and price (Carvalho et al. 2018).

\section{Conclusion}

To support brewers in uncovering the craft beer attributes more appealing to consumers, the study carried out an explorative analysis investigating the characteristics and preferences of craft beer consumers. Understanding consumers' preferences would enable to turn them into a product accepted on the market and able to meet craft beer consumers' expectations. To address the study aims, a structured questionnaire was administered to a non-probabilistic convenience sample of Italian consumers. While two sections of the questionnaire detected consumers' consumption habits and sociodemographic characteristics, the core of the questionnaire was the assessmentthrough a BWS experiment-of 13 craft beer attributes which are crucial in consumer purchasing decision.

The analysis revealed that craft beer consumers are younger, well educated, and with an annual family income in the range of $€ 20,000$ and 40,000. They drink craft beer monthly mainly in pub, after dinner, and with friends and colleagues. Craft beer is perceived with high quality, different flavor, tastier, more genuine, and natural than a commercial one. Lastly, consumers are willing to spend between 4 and 6 euros for a 33-cl bottle of craft beer. As for the craft beer attributes, consumers stated as most important taste, fermentation process, color, certification, and country of origin. By contrast, they are less interested in packaging material, store promotion, brand, and price.

The study findings offer several implications for brewers and marketers involved in the beer sector. As regards to consumers' characteristics, producers should convey their 
product offer to consumers with an age under 40 years, who consume beer weekly, that are well educated, and likely more adventurous to try new product and curious to acquire information about it. To appeal younger consumers, brewers may rely on attractive label or packaging; while to engage those eager to try new products, they may focus on new craft beers characterized by special grains (e.g., specialty beers or beers in limited editions). Considering the place of consumption mostly preferred by consumers (i.e., pub), brewers should invest and put more efforts to penetrate this promising distribution channel. For instance, breweries may put into place commercial initiatives directly in pub or restaurant, or they may differentiate their product offer (e.g., changing the product formula or packaging size) according to the different sales channels. Further, they may communicate their product in a way that pushes consumers to go out for a beer with friends and peers. To this extent, communication may portray people socializing in an informal and relaxing environment drinking a craft beer. Since taste came out, along with fermentation process, among the most important attributes selected by consumers when purchasing a craft beer, brewers should organize tasting initiatives directly in pub or restaurants in which consumers can experience the product and acquire information about its characteristics. Lastly, this analysis revealed the ineffectiveness of marketing strategy focused on price. Indeed, the attributes "store promotion" and "price" appear among the least important ones when purchasing a craft beer. Accordingly, brewers should devote more effort to product quality and the uniqueness of its characteristics.

The limitations of the study reside mainly in the sampling method adopted (i.e., nonprobabilistic), the limited number of interviews, and the attributes assessed. Therefore, future studies should implement a wider sample that may enable to segment consumers either on the basis of their generational cohorts or preferences for the different attributes. Future studies may also investigate the preference for craft beer attributes in two different consumer profiles such as heavy drinkers and light drinkers. The study is also limited by the selection of the attributes in the choice set as well as by the frame of some of the attributes (e.g., the fermentation process). Accordingly, further analysis should investigate different attributes or frame differently those investigated. Further, the B-W was outlined considering the purchase of craft beer in a grocery store. However, since the study results highlighted that craft beer is mainly purchased in pub or restaurant, future research may replicate this study considering these purchasing locations. Lastly, the hypothetical nature of the study may have affected consumers' preferences for some of the attributes investigated (e.g., store promotion, brand, and price).

Abbreviations

BIB: Balance incomplete block; B-W: Best-worst; BWS: Best-Worst Scaling

Authors' contributions

All authors read and approved the final manuscript.

Funding

Not applicable

Availability of data and materials

The dataset supporting this paper will be provided upon request. 
Received: 12 June 2019 Accepted: 16 September 2019

Published online: 02 April 2020

\section{References}

Aquilani B, Laureti T, Poponi S, Secondi L (2015) Beer choice and consumption determinants when craft beers are tasted: an exploratory study of consumer preferences. Food Qual Prefer 41:214-224

Auger P, Devinney TM, Louviere JJ (2007) Using best-worst scaling methodology to investigate consumer ethical beliefs across countries. J Bus Ethics 70:299-326

Boncinelli F, Dominici A, Gerini F, Marone E (2019) Consumers wine preferences according to purchase occasion: personal consumption and gift-giving. Food Qual Prefer 71:270-278

Burke P, Eckert C, Davis S (2014) Segmenting consumers' reasons for and against ethical consumption. Eur J Mark 48:22372261

Calvo-Porral C, Orosa-González J, Blazquez-Lozano F (2018) A clustered-based segmentation of beer consumers: from "beer lovers" to "beer to fuddle". Br Food J 120:1280-1294

Carvalho NB, Minim LA, Nascimento M, Ferreira GHDC, Minim VPR (2018) Characterization of the consumer market and motivations for the consumption of craft beer. Br Food J 120:378-391

Charters S, Pettigrew S (2007) The dimensions of wine quality. Food Qual Prefer 18:997-1007

Cohen E (2009) Applying best-worst scaling to wine marketing. Int J Wine Bus Res 21:8-23

Donadini G, Fumi MD, Kordialik-Bogacka E, Maggi L, Lambri M, Sckokai P (2016) Consumer interest in specialty beers in three European markets. Food Res Int 85:301-314

Donadini G, Porretta S (2017) Uncovering patterns of consumers' interest for beer: a case study with craft beers. Food Res Int 91:183-198

Finn A, Louviere JJ (1992) Determining the appropriate response to evidence of public concern: the case of food safety. J Public Policy Mark 11:12-25

Flynn TN, Louviere JJ, Peters TJ, Coast J (2007) Best-worst scaling: what it can do for health care research and how to do it. J Health Econ 26:171-189

Goodman S, Lockshin L, Cohen E (2008) Examining market segments and influencers of choice for wine using the Best-Worst choice method. Market Manage 8:94-112

Jaeger SR, Jørgensen AS, Aaslyng MD, Bredie WL (2008) Best-worst scaling: an introduction and initial comparison with monadic rating for preference elicitation with food products. Food Qual Prefer 19:579-588

Jover AJV, Montes FJL, Fuentes MDMF (2004) Measuring perceptions of quality in food products: the case of red wine. Food Qual Prefer 15:453-469

Lerro M, Raimondo M, Nazzaro C, Stanco M, Marotta G (2019) Cause related marketing among Millennial consumers: The role of trust and loyalty in the food industry. Sustainability 11:535-550

Louviere JJ, Islam T (2008) A comparison of importance weights and willingness-to-pay measures derived from choice-based conjoint, constant sum scales and best-worst scaling. J Bus Res 61:903-911

Lusk JL, Briggeman BC (2009) Food values. Am J Agric Econ 91:184-196

Marley AA, Louviere JJ (2005) Some probabilistic models of best, worst, and best-worst choices. J Math Psychol 49:464-480

McDonald LM, Rundle-Thiele S (2008) Corporate social responsibility and bank customer satisfaction: a research agenda. Int J Bank Mark 26:170-182

McFadden DL (1974) Conditional logit analysis of qualitative choice analysis. Front Econom:105-142

Mueller Loose S, Lockshin L (2013) Testing the robustness of best worst scaling for cross-national segmentation with different numbers of choice sets. Food Qual Prefer 27:230-242

Mueller S, Szolnoki G (2010) The relative influence of packaging, labelling, branding and sensory attributes on liking and purchase intent: consumers differ in their responsiveness. Food Qual Prefer 21:774-783

Muggah EM, McSweeney MB (2017) Females' attitude and preference for beer: a conjoint analysis study. J Food Sci Technol $52: 808-816$

Nazzaro C, Lerro M, Marotta G (2018) Assessing parental traits affecting children's food habits: an analysis of the determinants of responsible consumption. Agric Food Econ 6:23-36

Nazzaro C, Lerro M, Stanco M, Marotta G (2019) Do consumers like food product innovation? An analysis of willingness to pay for innovative food attributes. Br Food J. doi.org/10.1108/BFJ-06-2018-0389.

Poelmans E, Rousseau S (2017) Beer and organic labels: do Belgian consumers care? Sustainability 9:1509-1523

Pomarici E, Lerro M, Chrysochou P, Vecchio R, Krystallis A (2017) One size does (obviously not) fit all: using product attributes for wine market segmentation. Wine Economics and Policy 6:98-106

Sáenz-Navajas MP, Campo E, Sutan A, Ballester J, Valentin D (2013) Perception of wine quality according to extrinsic cues: the case of Burgundy wine consumers. Food Qual Prefer 27:44-53

Schäufele I, Hamm U (2018) Organic wine purchase behaviour in Germany: exploring the attitude-behaviour-gap with data from a household panel. Food Qual Prefer 63:1-11

The brewers of Europe (2018) Beer statistics 2018 edition. https://brewersofeurope.org/uploads/mycms-files/documents/ publications/2018/EU-beer-statistics-2018-web.pdf. Accessed 4 June 2019.

\section{Publisher's Note}

Springer Nature remains neutral with regard to jurisdictional claims in published maps and institutional affiliations. 